\title{
The prevalence of "pure" autosomal dominant hereditary spastic paraparesis in the island of Ireland
}

\author{
P Mc Monagle, S Webb, M Hutchinson
}

J Neurol Neurosurg Psychiatry 2002;72:43-46

See end of article for authors' affiliations

.....................

Correspondence to: Dr P Mc Monagle, Wessex

Neurological Centre,

Southampton General

Hospital, Tremona Road,

Southampton, SO16 6YD,

UK; pmcmon@eircom.net

Received 23 April 2001

In revised form 29 August

2001

Accepted 3 September

2001

\begin{abstract}
Objectives: Hereditary spastic paraparesis (HSP) is clinically and genetically heterogeneous. "Pure" autosomal dominant (AD) HSP is most common and eight genetic loci are identified to date. Previous studies have included autosomal recessive and sporadic cases in prevalence calculations. This study aimed to determine the prevalence and features of pure ADHSP in the island of Ireland.

Methods: Index cases were identified from a 5 year survey of all adult and paediatric neurologists, clinical geneticists, hospital records, and hospital inpatient enquiry system data in Ireland, north and south. Families were examined by two neurologists and classified as affected or unaffected according to specific criteria. The prevalence date was set at 1 June 2000 and the midyear population estimate for the previous year was 5.436 million.

Results: Eighty two patients with pure ADHSP and a further 12 obligate carriers from 19 families were identified. In total 69 patients with pure ADHSP were alive and resident in Ireland at the prevalence date. Twenty nine per cent of these were asymptomatic but with signs of paraparesis.

Conclusions: The prevalence of ADHSP in Ireland to estimated to be 1.27/100 000 population. The high proportion of asymptomatic cases and obligate carriers means that this condition is likely to be underdiagnosed.
\end{abstract}

$\mathrm{H}$ ereditary spastic paraparesis (HSP) comprises a group of inherited neurodegenerative disorders with the shared characteristic of slowly progressive spasticity and weakness of the legs. It is subdivided into "pure" or "complicated" forms depending on whether the paraparesis exists in isolation or with other major clinical features. ${ }^{12}$ Genetic heterogeneity is marked and autosomal dominant $(\mathrm{AD})$, autosomal recessive (AR), and $\mathrm{X}$ blinked inheritance is described for both pure and complicated forms. ${ }^{3}$ To date 16 genetic loci have been identified for all types of HSP. ${ }^{4-9}$ The most common form of HSP is pure ADHSP and even this is heterogeneous with eight loci identified. The most common cause of pure ADHSP, accounting for up to $40 \%$ of cases is a mutation in the SPAST gene on chromosome $2 \mathrm{p}^{10}$

The prevalence of HSP varies with different studies. Before Harding in 1983, the distinction between pure and complicated forms changed from study to study and prevalence rates varied consequently. Since then, reports have tended to include autosomal recessive forms and sporadic cases in their calculations. To date there has been no study looking at pure ADHSP alone. The aim of our study therefore was to examine the prevalence of all cases of pure ADHSP in the island of Ireland as this represents the most homogeneous group within the disorder.

\section{METHODS}

\section{Study area}

The island covers an area of $84433 \mathrm{~km}^{2}$ and comprises the Republic of Ireland and Northern Ireland, which is part of the United Kingdom. In 1999, the midyear estimate of the population was 3.7447 million for the Republic of Ireland and 1.6918 million for Northern Ireland giving 5.436 million in total. ${ }^{11}$ The latest year in which population estimates are available for Northern Ireland is 1999 and the eight regional authorities in the Republic of Ireland and regional rates are compared on this basis.

\section{Case ascertainment}

We undertook a prospective, population based study of HSP in Ireland over 5 years from July 1995 to 1 July 2000. Index cases, identifying potential HSP pedigrees, were identified from four sources; (1) adult and paediatric neurologists; (2) clinical geneticists; (3) review of hospital records of four major neurological centres in Ireland and (4) the Hospital Inpatient enquiry system (HIPE).

All index cases were seen and examined by two neurologists independently and blood was taken for genetic analysis. Any family members with gait disturbance and as many other first and second degree relatives as possible were also seen and examined. Families were considered to show autosomal dominant inheritance if there was vertical and male to male transmission with equal numbers of males and females affected. Patients were considered resident if they had been living in the region for at least one year at the prevalence date.

\section{Diagnostic criteria}

We used the diagnostic criteria of Fink et al. ${ }^{12}$ Subjects were considered definitely affected with HSP if (1) alternative disorders had been excluded; (2) a family history supported inheritance of an autosomal dominant disorder; (3) subjects reported a progressive disturbance of gait; and (4) neurological examination showed frank corticospinal tract deficits in the legs, hyperreflexia with clonus and extensor plantar responses. Probably affected persons were those with pyramidal signs and extensor plantars but who remained asymptomatic. Possibly affected members were asymptomatic at risk persons with a questionably abnormal neurological examination (mild hyperreflexia, a few beats of unsustained ankle clonus, and flexor plantar responses). Only cases with definite or probable pure HSP were included in calculations. A third neurologist $(\mathrm{MH})$ acted as arbiter when the diagnostic criteria were ambiguous, although in practice this was only necessary once. Cases were classified as having pure or complicated HSP

Abbreviations: HSP, hereditary spastic paraparesis; $A D$, autosomal dominant; $A R$, autosomal recessive; HIPE, hospital in patient enquiry system; PR, pevalence rate 
Table 1 Age specific prevalence of "pure" AD-HSP in Ireland

\begin{tabular}{|c|c|c|c|c|c|c|c|c|c|c|c|c|}
\hline \multirow[b]{2}{*}{ Age } & \multicolumn{4}{|l|}{ Female } & \multicolumn{4}{|l|}{ Male } & \multicolumn{4}{|l|}{ Total } \\
\hline & Popn (m) & $\mathrm{n}$ & $\begin{array}{l}\text { Rate/ } \\
100000\end{array}$ & $95 \% \mathrm{Cl}$ & Popn (m) & $\mathrm{n}$ & $\begin{array}{l}\text { Rate/ } \\
100000\end{array}$ & $95 \% \mathrm{Cl}$ & Popn (m) & $\mathrm{n}$ & $\begin{array}{l}\text { Rate / } \\
100000\end{array}$ & $95 \% \mathrm{Cl}$ \\
\hline $0-9$ & 0.3794 & 2 & 0.53 & 0.06 to 1.9 & 0.4002 & 3 & 0.75 & 0.15 to 2.19 & 0.7796 & 5 & 0.64 & 0.21 to 1.5 \\
\hline 10-19 & 0.4408 & 3 & 0.68 & 0.14 to 1.99 & 0.4638 & 6 & 1.29 & 0.47 to 2.82 & 0.9046 & 9 & 0.99 & 0.45 to 1.89 \\
\hline $20-29$ & 0.417 & 4 & 0.96 & 0.26 to 2.46 & 0.4292 & 4 & 0.93 & 0.25 to 2.39 & 0.8462 & 8 & 0.95 & 0.41 to 1.86 \\
\hline $30-39$ & 0.3995 & 6 & 1.5 & 0.55 to 3.27 & 0.3887 & 5 & 1.29 & 0.42 to 3.0 & 0.7882 & 11 & 1.40 & 0.7 to 2.5 \\
\hline $40-49$ & 0.3492 & 4 & 1.15 & 0.31 to 2.93 & 0.3459 & 9 & 2.6 & 1.19 to 4.94 & 0.6951 & 13 & 1.87 & 1.0 to 3.2 \\
\hline $50-59$ & 0.2813 & 3 & 1.07 & 0.22 to 3.12 & 0.2828 & 3 & 1.06 & 0.22 to 3.1 & 0.5641 & 6 & 1.06 & 0.39 to 2.32 \\
\hline $60-69$ & 0.211 & 8 & 3.79 & 1.64 to 7.47 & 0.1982 & 4 & 2.02 & 0.55 to 5.17 & 0.4092 & 12 & 2.93 & 1.52 to 5.12 \\
\hline 70-79 & 0.1735 & 3 & 1.73 & 0.36 to 5.05 & 0.1299 & 2 & 1.54 & 0.19 to 5.56 & 0.3034 & 5 & 1.65 & 0.53 to 3.85 \\
\hline $80+$ & 0.097 & 0 & 0.0 & 0.0 to 3.8 & 0.049 & 0 & 0.0 & 0.0 to 7.53 & 0.1459 & 0 & 0.0 & 0.0 to 2.53 \\
\hline Age adjusted total & 2.7487 & 33 & 1.19 & 0.83 to 1.69 & 2.6877 & 36 & 1.33 & 0.94 to 1.85 & 5.4363 & 69 & 1.27 & 0.99 to 1.61 \\
\hline
\end{tabular}

using the criteria of Harding. ${ }^{12}$ Cases with mild ataxia and mild distal amyotrophy as well as late onset dementia were considered to have pure HSP as these are uncommon but recognised findings in patients with SPAST mutations, the major disease gene for pure ADHSP.

\section{Statistical methods}

A point prevalence was calculated using the 1999 midyear estimate of the population of the Republic of Ireland and Northern Ireland as the denominator. Age, sex, and region specific rates were calculated with $95 \%$ confidence intervals (95\% CIs) derived from the Poisson distribution to allow for sampling errors. Regional variation was analysed with a one sample $z$ test and rates were age adjusted to the overall population using the direct method.

\section{RESULTS}

In total, we identified 82 people with signs of paraparesis from 19 Irish families with pure ADHSP. The major source of index cases was from neurologists $(n=15)$, followed by clinical geneticists $(n=3)$, and search of hospital records $(n=1)$, and the HIPE reporting system disclosed no additional cases. Four families demonstrated mutations in the SPAST gene on chromosome $2 p(n=16)$, a further family $(n=10)$ did not have an identifiable mutation in this gene despite evidence of strong linkage to SPG4 (maximum lod score $=3.86$ at zero recombination). In three families involvement of SPAST was excluded $(n=22)$ whereas the genetic status of the remaining 11 families $(n=22)$ could not be determined. Clinical and genetic details of these families are described elsewhere. ${ }^{13} 14$
At prevalence day, eight affected people were living abroad though they had all emigrated before the study began. Another five had died towards the middle of the study period, leaving 69 alive and resident in Ireland, which gives a crude prevalence of 1.2/100 000 population (95\% CI 0.99 to 1.61 ). Thirty three females were affected (age adjusted prevalence $=1.19 / 100000,95 \%$ CI 0.83 to 1.69 ) and 36 males (age adjusted prevalence $=1.33 / 100000,95 \%$ CI 0.94 to 1.85 ) with no significant difference between the rate for either group $(z=0.3)$. The age and sex prevalence of ADHSP is illustrated in table 1 . A higher prevalence is seen for men aged 40 to $49(\mathrm{z}=0.14, \mathrm{p}=0.8)$ and for women aged 60 to 69 $(z=-0.105, p=0.92)$ but this was not statistically significant for either. Twenty of the 69 with signs of HSP were asymptomatic $(29 \%)$ and therefore unaware of any abnormality. These cases were only detected through examination of the extended family in each case. A further 12 people were thought to be obligate gene carriers based on haplotype, mutation, and family tree analysis but were not included in data calculations.

Relative prevalence rates for each regional authority are outlined in figure 1. The Dublin area had the highest rate of pure ADHSP at 2.46/100 000 population (95\% CI 1.48 to 3.37 ). This was significantly higher than the overall population rate $(z=3.51, p<0.01)$ and persisted after adjustment for age. This is the capital of the Republic of Ireland and the main population centre for the entire island. The lowest rate was found in the border region between Northern Ireland and Republic of Ireland $(0.24 / 100000 ; 95 \%$ CI 0.06 to 1.36$)$.

Table 2 Prevalences in previous studies of hereditary spastic paraparesis

\begin{tabular}{|c|c|c|c|c|c|c|c|c|}
\hline Author & $\begin{array}{l}\text { Period of } \\
\text { study }\end{array}$ & Area of study & Population & Patient sources & $\begin{array}{l}\text { Clinical } \\
\text { features }\end{array}$ & Inheritance & $\begin{array}{l}\text { Cases } \\
\text { (n) }\end{array}$ & $\begin{array}{l}\text { Prevalence/ } \\
100000\end{array}$ \\
\hline Chen et al ${ }^{15}$ & $1960-1966$ & Guam & 37975 & $\begin{array}{l}\text { National Institute of Neurological Diseases and } \\
\text { Blindness }\end{array}$ & Pure & $\begin{array}{l}\text { AD/AR-HSP and } \\
\text { sporadic }\end{array}$ & 7 & 18.4 \\
\hline Skre ${ }^{16}$ & $1960-1968$ & Western Norway & 725000 & University hospital in Bergen & $\begin{array}{l}\text { Pure and } \\
\text { complicated }\end{array}$ & AD-HSP & 31 & 12.1 \\
\hline \multirow{2}{*}{$\begin{array}{l}\text { Werderlin }{ }^{17} \\
\text { Werderlin and } \\
\text { Keiding }^{18}\end{array}$} & \multirow[t]{2}{*}{$1961-1975$} & \multirow[t]{2}{*}{ Zealand (Denmark) } & 1179000 & \multirow[t]{2}{*}{ All hospitals in Zealand } & \multirow{2}{*}{$\begin{array}{l}\text { Pure and } \\
\text { complicated }\end{array}$} & \multirow[t]{2}{*}{ AD/AR-HSP } & \multirow[t]{2}{*}{23} & \multirow[t]{2}{*}{2} \\
\hline & & & Age 10 to 50 & & & & & \\
\hline Brignoli et al ${ }^{19}$ & $1945-1982$ & Turin (Italy) & 2327996 & $\begin{array}{l}\text { District and regional hospitals, nursing homes and } \\
\text { disability centres }\end{array}$ & Not stated & AD-HSP & 31 & 0.7 \\
\hline Sridharan et a ${ }^{20}$ & 1984 & Benghazi (Libya) & 519000 & $\begin{array}{l}\text { Polyclinics, disability centres and four university } \\
\text { hospitals }\end{array}$ & $\begin{array}{l}\text { Pure and } \\
\text { complicated }\end{array}$ & $\begin{array}{l}\text { AD/AR-HSP and } \\
\text { sporadic }\end{array}$ & 11 & 2.1 \\
\hline Polo et a ${ }^{1}$ & $1974-1986$ & Cantabria (Spain) & 510000 & Neurology department of the regional hospital & Pure & AD/AR-HSP & 49 & 9.6 \\
\hline Fllla et a ${ }^{22}$ & 1989 & Molise (Italy) & 335211 & $\begin{array}{l}\text { Mail and phone survey of } 847 \text { hospital physicians } \\
\text { and GPs }\end{array}$ & $\begin{array}{l}\text { Pure and } \\
\text { complicated }\end{array}$ & AD/AR-HSP & 9 & 2.7 \\
\hline Hirayama et $a^{23}$ & 1988-1989 & Japan & 123000000 & Mail survey of hospitals with 200 plus beds & $\begin{array}{l}\text { Pure and } \\
\text { complicated }\end{array}$ & $\begin{array}{l}\text { AD/AR-HSP and } \\
\text { sporadic }\end{array}$ & 109 & 0.17 \\
\hline Leone et $a^{24}$ & $1981-1991$ & Valle d'Aosta (Italy) & 115270 & $\begin{array}{l}\text { Departments in the regional hospital and local } \\
\text { disability centres }\end{array}$ & Pure & $\begin{array}{l}\text { AD-HSP and } \\
\text { sporadic }\end{array}$ & 5 & 4.3 \\
\hline Silva et $a^{25}$ & 1994 & $\begin{array}{l}\text { Viano do Castelano } \\
\text { (Portugal) }\end{array}$ & 250061 & $\begin{array}{l}\text { District \& regional hospitals, disability centres and } \\
\text { GPs }\end{array}$ & $\begin{array}{l}\text { Pure and } \\
\text { complicated }\end{array}$ & AD/AR-HSP & 5 & 2 \\
\hline Current study & $1995-2000$ & Ireland & 5436000 & Neurologists, geneticists, and hospital records. & Pure & AD-HSP & 69 & 1.27 \\
\hline
\end{tabular}




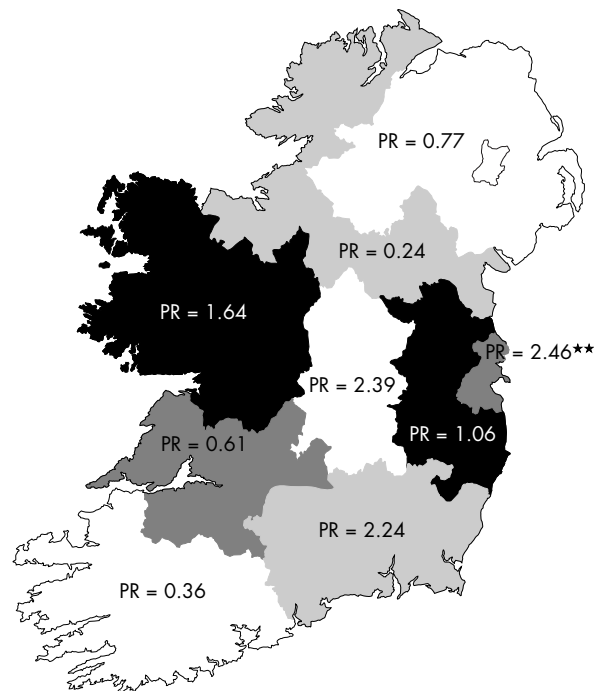

Figure 1 Prevalence rates (PRs)/ 100000 population for each region of Ireland. The rate for the Dublin area is significantly higher than elsewhere.

\section{CONCLUSIONS}

In the course of a 5 year population based survey of HSP in the north and south of Ireland we identified 69 cases with pure ADHSP to give a crude point prevalence of 1.27/100 000. Equal prevalence was seen for both men and women in keeping with autosomal inheritance. Regional variation showed the greatest numbers in the Dublin area with 2.46/100 000 population. The accuracy of this estimate of pure ADHSP prevalence depends on the complete ascertainment of all cases in Ireland. Capture-recapture analysis based on multiple sources can be used to estimate this but was not suited to our study. Multiple sources identified each family rather than each case and the sources themselves were not truly independent. Active family tracing by the investigators gave the final count and acted effectively as a single source. In addition, the high proportion of asymptomatic cases (29\%) means complete ascertainment is unlikely to be achieved and any prevalence determined will probably be an underestimate. Other difficulties arise because of the potential for misdiagnosis, not considering HSP as a possible diagnosis, and the failure to examine relatives of patients with apparently sporadic pure spastic paraparesis. Primary progressive multiple sclerosis, cerebral palsy and arthritis are common diagnostic errors that arise if patients are not seen by a neurologist. However, we think that we have ascertained all cases of pure ADHSP that came to neurological attention, certainly in the Dublin area, as well as a significant proportion of other cases from direct examination of at risk family members. There are only a few neurologists in Ireland. All were written to annually during the study period and all replied either verbally or in writing to our requests for patients thus providing the major source for our families. Only one additional case was disclosed from review of the medical records in four neurological centres in Ireland whereas the HIPE reporting system disclosed none.

The highest rates of pure ADHSP are found in the Dublin area which is not surprising because it is the main population centre ( $20 \%$ of the entire island) and has the highest number of neurologists $(n=9)$ in the country. We found no evidence that patients with HSP migrated to population centres such as Dublin for treatment or for any other reasons beyond the usual socioeconomic forces. This was evident through direct questioning and review of records and was facilitated by knowing the whereabouts of other family members, parents, and the original family home. Many patients were unaware of any abnormality and therefore required no medical input.
Those who did, contacted the health services primarily for diagnosis and most were not routinely followed up in neurology clinics. In all cases, those who did attend for physiotherapy or adjustment of medications lived within easy driving distance ( 3 hours maximum) so migration for treatment or assessment was not necessary. Another factor militating against migration is the relatively late onset of symptoms. In SPAST pedigrees, this is usually between the ages of 28 and 30 when many have married and started families making movement difficult. Other potential reasons for geographic variation, beyond chance, would include racial differences in the population distribution between regions. This did not apply in our study as all cases and families were the same race. Environmental exposure to toxins or infections in urban areas, causing spontaneous mutations in HSP genes, is another possible cause. However, the frequent finding of gait disturbance in family members, living in rural areas, dating back generations argues against this. Another factor is difference in diagnostic and referral practice between regions and physicians and this we think is more likely to be significant. Patients were frequently misdiagnosed as having multiple sclerosis or arthritis before being seen by a neurologist. The concentration of neurologists in the Dublin area all meet on a weekly basis which means that they were more likely to refer patients to the study, which was based in a Dublin teaching hospital. We think, therefore, that the higher rates of HSP in the Dublin area probably reflect a greater likelihood of being diagnosed with HSP and referred to the study. Consequently, while still probably an underestimate, we think that the prevalence rate here gives the best estimate of the "true" rate of pure ADHSP in Ireland as a whole.

Comparison with other prevalence studies in HSP is fraught with difficulty because they are not often performed and lack uniformity of diagnostic criteria. Some authors include apparently sporadic cases in their calculations of HSP prevalence and others include complicated with pure cases and autosomal recessive with dominant families. It is not surprising, therefore, that our rate falls in the lower end of the reported range of HSP prevalence (table 2) ${ }^{15-25}$ However, the prevalence rate for the Dublin area $(2.46 / 100$ 000; $95 \%$ CI 1.48 to 3.37 ) is consistent with the reports of others. ${ }^{18} 202225$ Ours is the first prospective study to examine the prevalence of pure ADHSP in an entire country using specific classification and diagnostic criteria and excluding those with recessive inheritance or complicated phenotypes. It is clear that even pure ADHSP represents more than one disease and our study therefore reflects the frequency of a particular phenotype rather than a specific disease. In the future prevalence studies will be based on the presence of specific gene mutations, but for uncommon, genetically heterogeneous disorders such as HSP this is not yet possible.

\section{ACKNOWLEDGEMENTS}

We are grateful to patients and their families for their participation and all adult and paediatric neurologists in Ireland, north and south, who have referred patients for the study.

\section{Authors' affiliations}

P Mc Monagle, S Webb, M Hutchinson, Department of Neurology, St Vincent's University Hospital, Elm Park, Dublin 4, Ireland

\section{REFERENCES}

1 Harding AE. Hereditary "pure" spastic paraplegia: a clinical and genetic study of 22 families. $1981 ; 44: 871-83$.

2 Harding AE. Classification of the hereditary ataxias and paraplegias. Lancet 1983;i:1151-5.

3 Reid E. The hereditary spastic paraplegias. J Neurol 1999;246:9951003.

4 McDermott CJ, White K, Bushby K, et al. Hereditary spastic paraparesis: a review of new developments. J Neurol Neurosurg Psychiatry 2000;69:150-60. 
5 Fontaine B, Davoine C-S, Dürr A, et al. A new locus for autosomal dominant pure spastic paraplegia on chromosome 2q24-q34. Am J Hum Genet 2000;66:702-7

6 Reid E, Dearlove AM, Osborn O, et al. A locus for autosomal dominant "pure" spastic paraplegia maps to chromosome 19q13. Am J Hum Genet 2000;66:728-32.

7 Vazza G, Zortea M, Boaretto F, et al. A new locus for autosomal recessive spastic paraplegia associated with mental retardation and distal motor neuropathy, SPG14, maps to chromosome 3q27-q28. Am J Hum Genet 2000;67:504-9.

8 Tamagaki A, Shima M, Tomita R, et al. Segregation of a pure form of spastic paraplegia and NOR insertion into Xq 1 1.2. Am J Med Genet 2000;94:5-8.

9 Hughes CA, Byrne PC, Webb S, et al. A new locus for autosomal recessive complicated hereditary spastic paraparesis on chromosome 14q. Neurology 2001;56:1230-3.

10 Fonknechten N, Mavel D, Byrne P, et al. Spectrum of SPG4 mutations in autosomal dominant spastic paraplegia. Hum Mol Genet 2000;9:637-44.

11 Central Statistics Office and Northern Ireland Statistics and Research Agency. Ireland north and south, a statistical profile. Cork and Belfast, Ireland: CSO and NISRA, 2000:88

12 Fink JK, Heiman-Patterson T, Bird T, et al. Hereditary spastic paraplegia: advances in genetic research. Hereditary spastic paraplegia working group. Neurology 1996:46:1507-14.

13 Mc Monagle P, Byrne P, Fitzgerald B, et al. The phenotype of autosomal dominant hereditary spastic paraparesis due to mutations in the SPAST gene: comparison with AD-HSP without mutations. Neurology 2000;55: 1794-800
14 Webb S, Coleman D, Byrne P, et al. Autosomal dominant hereditary spastic paraparesis with cognitive loss linked to chromosome 2p. Brain 1998;121:601-9.

15 Chen K, Brody JA, Kurland LT. Patterns of neurological disease on Guam. Arch Neurol 1968;19:573-8.

16 Skre H. Hereditary spastic paraplegia in western Norway. Clin Genet 1974;6:165-83

17 Werderlin L. Hereditary ataxias: occurrence and clinical features. Acta Neurol Scand 1986;106(suppl): 1-124.

18 Werderlin L, Keiding N. Hereditary ataxias: epidemiological aspects Neuroepidemiology 1990;9:321-31.

19 Brignoli F, Leone M, Tribolo A, et al. Prevalence of hereditary ataxias and paraplegias in the province of Torino, Italy. Ital J Neurol Sci 1986:7:431-5.

20 Sridharan R, Radhakrishnan K, Ashok PP, et al. Prevalence and pattern of spinocerebellar degenerations in northeastern Libya. Brain 1985; 108:831-43

21 Polo JM, Calleja J, Combarros O, et al. Hereditary ataxias and paraplegias in Cantabria, Spain. Brain 1991;114:855-66.

22 Filla A, DeMichele G, Marconi R, et al. Prevalence of hereditary ataxias and spastic paraplegias in Molise, a region of Italy. J Neurol 1992;239:351-3.

23 Hirayama K, Takayanagi T, Nakamura R, et al. Spinocerebellar degenerations in Japan: a nationwide epidemiological study. Acta Neurol Scand 1994;153(suppl): 1-22.

24 Leone M, Bottachi E, D'Allesandro G, et al. Hereditary ataxias and paraplegias in Valle d'Aosta, Italy: a study of prevalence and disability. Acta Neurol Scand 1995;91:183-7.

25 Silva MC, Countinho P, Pinheiro CD, et al. Hereditary ataxias and spastic paraplegias: methodological aspects of a prevalence study in Portugal. J Clin Epidemiol 1997;50:1377-84.

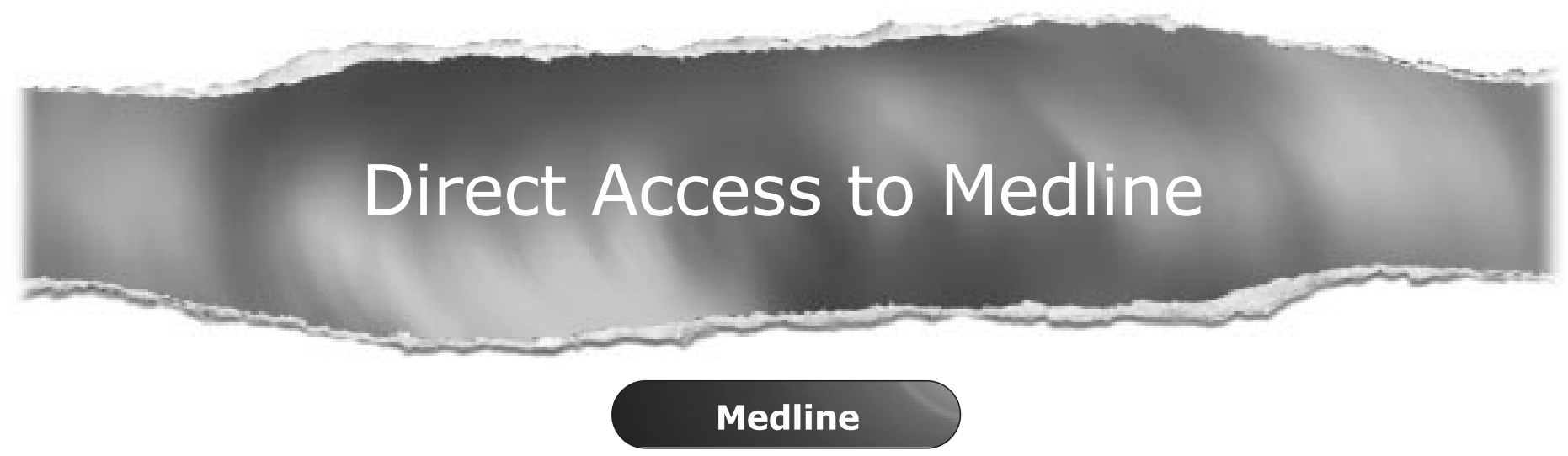

Link to Medline from the homepage and get straight into the National Library of Medicine's premier bibliographic database. Medline allows you to search across 9 million records of bibliographic citations and author abstracts from approximately 3,900 current biomedical journals.

\section{www.jnnp.com}

